Katrina Mirabito Colafella

NHMRC CJ Martin Fellow and Cardiovascular Program Emerging Leader, Biomedicine Discovery Institute, Department of Physiology, Monash University, Melbourne, Australia

\author{
Visiting Fellow, Division of Vascular Medicine and \\ Pharmacology, Department of Internal Medicine, \\ Erasmus Medical Centre, Rotterdam, The Netherlands
}

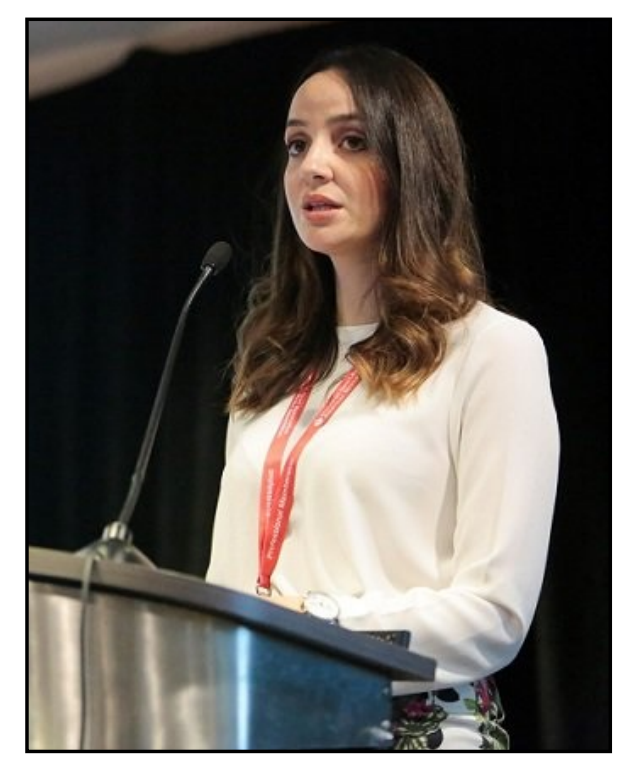

ISH 2018 was a four-day event in the bustling city of Beijing (there are nearly as many people in Beijing as there are in the whole of Australia!) bringing together researchers from all over the globe. As an invited speaker for one of the joint European Council for Cardiovascular Research (ECCR)/High Blood Pressure Council of Australia (HBPRCA) breakfast workshop sessions and it was an honour to able to present my latest work on angiogenesis inhibitor-induced hypertension. This area of research is in the rapidly growing cardio-oncology field which is aimed at minimising the effects of cardiovascular morbidity and mortality in cancer patients. Many thanks to the ISH and the HBPRCA for supporting my attendance at the conference.

I really enjoyed the breakfast sessions. In the Meet the Experts Session with Prof Dominique Müller we were given a fantastic overview of the role of salt accumulation in the skin and the development of hypertension. This was of interest to me as salt accumulation in the skin has been investigated as a possible mechanism contributing to angiogenesis inhibitor-induced hypertension. There was also a great session on hypertension and cardiovascular disease in women, where Prof Kate Denton, who was awarded the inaugural ISH Award of Excellence for Research in Cardiovascular Health and Disease in Women, gave a wonderful talk on sex-specific differences in hypertension.

One of the highlights of the meeting was the
Women in Hypertension Research-Maximising Opportunities and Researching Career Goals session chaired by Prof Rhian Touyz and Dr Sofie Brouwers. Dr Clara Chow and our new ISH President, Prof Alta Schutte, spoke about the opportunities and challenges they faced in developing their research careers as a clinician-scientist and basic researcher, respectively. It was fascinating to hear how these two women built their research careers, raised families and maintained their own work/life balance. The panel discussion at the end was a great opportunity for the audience to ask questions and voice concerns about their career in a supportive environment. I think everyone who attended really enjoyed this session.

The future of hypertension was also a hot topic. Our outgoing ISH President, Prof Neil Poulter gave a passionate address about the importance of hypertension awareness, initiatives such as May Measurement Month and how we need to change how people perceive hypertension. While in the Plenary Session, Prof Victor Dzau spoke about the future of healthcare and novel therapies for hypertension such as siRNA. This is something that is already in the pipeline, with preclinical work investigating the antihypertensive efficacy of liver-targeted angiotensinogen siRNA presented at this year's ISH meeting. I look forward to seeing where the field has progressed to when we meet again at the ESH-ISH 2020 Joint Meeting in Glasgow! 


\section{ISH 2018 New Investigator Pre-Meeting Symposium}

The ISH 2018 New Investigator Pre-Symposium on 20 September, was held at the iconic Bird's Nest venue in Beijing (attendees pictured right). The

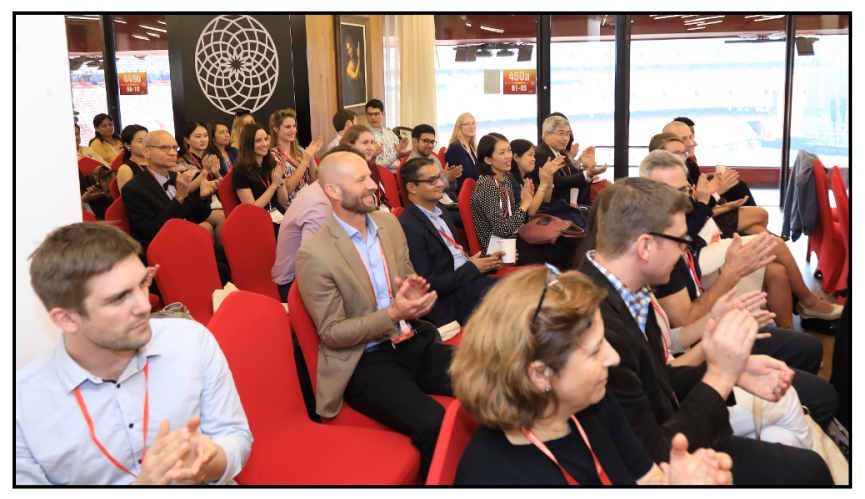
event was attended by more than 70 people, including our ISH Distinguished Mentor awardees, ISH Council members, senior faculty and junior investigators. Participants originated from 24 countries.

The afternoon kicked off with welcome drinks and canapes followed by two fantastic presentations from the inaugural ISH Distinguished Mentor Awardees: Prof Jan Danser from The Netherlands and Prof James Sharman from Australia. The ISH Distinguished Mentor Award was established to recognise the contribution of mentors to the growth and development of junior investigators. Prof Danser shared his insights into what it takes to become a successful independent researcher in

\begin{tabular}{|cl|}
\hline F & Fact checking \\
I & Internationalize your group \\
N & Never alone in the lab \\
A & Authorship \\
N & N-numbers \\
C & Collaborate outside the lab \\
I & International meeting attendance \\
N & Network \\
G & Go abroad \\
\hline
\end{tabular}

today's age and summed it all up in a clever acrostic (Figure 1). Following this, Prof Sharman shared his thoughts and experiences on successful mentoring relationships and what to look for in a mentor.

The second part of the Pre-Symposium program consisted of a panel discussion with Nadia Khan (Canada), Dylan Burger (Canada), Maciej Tomaszewski (UK), Brandi Wynne (USA) and Jolanta Malyszko (Poland). These researchers represented various career stages and points of view based on their geographic locations and specialities and as a

Figure 1

panel they happily fielded questions from the audience. This turned into a lively discussion with senior faculty members Prof Neil Poulter, Prof Lars Lindholm and our ISH Distinguished Mentors contributing their thoughts on a range of topics including the next hot topics in hypertension research, when are you an independent researcher and whether to invest in the latest techniques, use core facilities or outsource your work. Following the panel discussion, we enjoyed the stunning location and mingled with friends and colleagues. This latter part of the afternoon was an excellent opportunity to meet new people and establish collaborations in a relaxed environment.

The ISH2018 New Investigator Pre-Symposium was truly a wonderful event and I highly recommend that all junior investigators attend future ISH New Investigator events, either at one of our affiliated meetings or the next ISH meeting which will be held in Glasgow in 2020.

Finally, on behalf of all of the attendees, I would like to thank our Distinguished Mentor Awardees, the panel members and senior faculty members for sharing with us their career advice and insights into the future of hypertension research. To the organising committee, including ISH Council Members, the ISH New Investigator Committee and Helen Horsfield (ISH Secretariat), thank you for all of the hard work that went into putting this Pre-Symposium together and for making the afternoon an event to remember. 